\title{
Determining Bishop's parameter $\chi$ based on pore size distribution
}

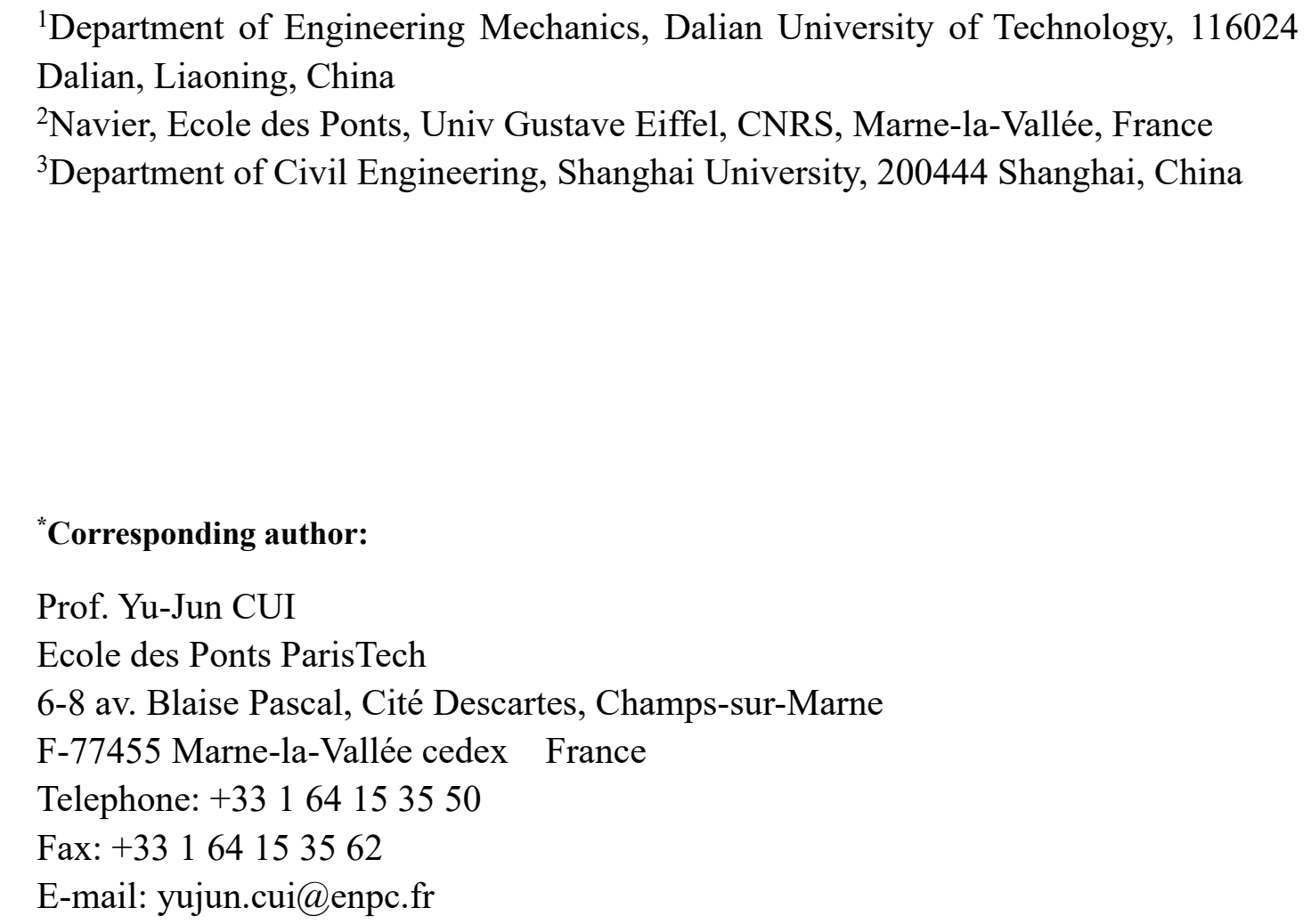




\section{Abstract}

29 Extension of the effective stress concept to unsaturated soils has been a major concern

30 for decades. Recent studies significantly contributed to the understanding of the

31 fundamentals behind Bishop's parameter $\chi$ which is generally used to define the

32 effective stress for unsaturated soils. Examination of the recently proposed methods

33 showed that the contribution of suction to effective stress was often overestimated,

34 especially in high suction range. In this study, considering that soil pores with different

35 sizes contribute differently to the overall hydro-mechanical behaviour, a new method

36 to determine Bishop's parameter $\chi$ is proposed. The key variable used in this method

37 is the ratio of the change in water volume to the change in macro-pore void volume

38 due to loading at constant suction. Shear strength data for a weakly expansive clay

39 were used for validation. A good agreement was obtained between prediction and

40 measurement, indicating the validity of the proposed method.

41

42 Keywords:

43 constitutive relations; fabric/structure of soils; shear strength; partial saturation;

44 suction 


\section{NOTATION}

$46 e_{\mathrm{w} 2} \quad$ water ratio caused by change of strain at constant suction

$47 \quad e_{\mathrm{w}}^{m} \quad$ microscopic water ratio

$48 e^{\mathrm{m}} \quad$ microscopic void ratio

$49 S_{\mathrm{r}}^{\mathrm{e}} \quad$ effective degree of saturation

$50 \quad S_{\mathrm{r}}^{\mathrm{m}} \quad$ microscopic degree of saturation

$51 S_{\mathrm{r}}^{\mathrm{cap}} \quad$ capillary degree of saturation

$52 S_{\mathrm{r}}^{\text {ads }}$ adsorbed degree of saturation

$53 \quad s_{\mathrm{m}} \quad$ suction corresponding to the median pore diameter

$54 \quad V_{\mathrm{w} 1} \quad$ water volume governed by suction

$55 \alpha \quad$ ratio of the change in incremental water volume caused by the change of

56 strain under constant suction to total pore volume increment

$57 \quad \lambda \quad$ material parameter defining the effective degree of saturation

$58 \quad \xi \quad$ standard deviation of the log-transformed pore radius

$59 \varphi \quad$ fitting parameter related to the theoretical degree of saturation due to

$60 \quad$ adsorption at $1 \mathrm{kPa}$ suction

$61 \chi \quad$ Bishop's effective stress parameter

62 
The definition of stress variables is essential in developing constitutive models for unsaturated soils. There are two approaches for modeling their mechanical behaviour: the effective stress approach (Bishop, 1959) and the two independent state variables approach (Coleman 1962, Fredlund \& Morgenstern, 1977). Currently, using two independent stress variables to describe the behavior of unsaturated soils is widely accepted (Cui and Delage, 1996; Wheeler et al., 2003; Liu et al., 2018). Bishop stress is often considered as one variable in the two independent stresses approach, because

71 it represents a smooth extension of Terzaghi's effective stress (Sheng et al., 2004; Pereira et al., 2005; Zhou et al., 2018). In the Bishop's effective stress concept, the

73 key parameter is $\chi$, as shown in Eq. 1 (Bishop, 1959):

$$
\sigma^{\prime}=\sigma-\left[\chi u_{\mathrm{w}}+(1-\chi) u_{\mathrm{a}}\right]
$$
where $\sigma^{\prime}$ is unsaturated effective stress; $\sigma$ is total stress; $\chi$ is the effective stress

76 parameter (Bishop's parameter); $u_{\mathrm{w}}$ and $u_{\mathrm{a}}$ are water and air pressures, respectively. early contributions (Bishop \& Blight, 1963), $\chi$ was set equal to degree of saturation $S_{\mathrm{r}}$ :

$$
\chi=S_{\mathrm{r}}
$$

80 which is the simplest, and most used assumption to date. But several studies showed

81 that this choice significantly overestimates the contribution of suction to effective 82 stress, especially in the high suction range (Sheng et al., 2011; Zhou et al., 2016). In 83 a later effort, the overestimation was reduced by using an effective degree of 84 saturation (Vanapalli et al., 1996). To define this latter, attempts have been made to 
87 where $\lambda \geq 1$ is a material parameter. For coarse-grained soils, parameter $\lambda$ is almost

directly relate $\chi$ to the total degree of saturation, such as (Vanapalli et al., 1996):

$$
\chi=f\left(S_{\mathrm{r}}\right)=\left(S_{\mathrm{r}}\right)^{\lambda}
$$
equal to unity, while for fine-grained soils $\lambda$ is larger than unity. Garven $\&$ Vanapalli (2006) found that $\lambda$ is correlated with plasticity index, $I_{\mathrm{p}}$.

Soil water consists in capillary water and adsorbed one. Since adsorbed water is strongly bonded to soil particles (Lu et al., 2010; Konrad \& Lebeau, 2015; Zhou et al., 2016; Gao et al., 2018), it does not contribute to the contact stress and thus to the effective stress. Thereby, Zhou et al. (2016) related the Bishop's parameter $\chi$ to the capillary degree of saturation $S_{\mathrm{r}}^{\mathrm{cap}}$ which is the difference between the total degree of saturation and the adsorbed degree of saturation $S_{\mathrm{r}}^{\text {ads }}$ :

$$
\chi=S_{\mathrm{r}}^{\mathrm{cap}}=\frac{\mathrm{C}(s)-\varphi \mathrm{C}(s) \mathrm{A}(s)}{1-\varphi \mathrm{C}(s) \mathrm{A}(s)}
$$

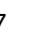

$$
\text { with } C(\mathrm{~s})=\frac{1}{2} \operatorname{erfc}\left[\frac{\ln \left(s / s_{\mathrm{m}}\right)}{\sqrt{2} \xi}\right], A(\mathrm{~s})=1-\frac{\ln (s)}{\ln \left(s_{\mathrm{d}}\right)}
$$

where $s$ is matric suction; $\varphi$ and $\xi$ are fitting parameters determined by soil water retention curve (SWRC); $s_{\mathrm{m}}$ is the suction which corresponds to the median pore diameter; $s_{\mathrm{d}}$ is the suction at extreme dry state, assumed equal to $10^{6} \mathrm{kPa}$. However, the lastest investigation showed that using capillary degree of saturation underestimates the contribution of suction to Bishop's effective stress for most soils (Gao et al., 2020). It has been well documented that for compacted soils, the microstructure is characterised by two pore populations: i) macro-pores where capillary effects dominate, and ii) micro-pores where the hygroscopic effect dominates (Romero \& Vaunat, 2000; Alonso et al., 2010). It has been admitted that 

trapped in macro- or inter-aggregate pores (Alonso et al., 2010; Zhai et al., 2019).

109 This was confirmed by some experimental results which showed that loading and 110 drying paths predominantly influenced the macropores, while micropores remain 111 almost undisturbed (Monroy et al., 2010; Mašín, 2013). Therefore, Bishop's 112 parameter $\chi$ can be considered as the effective degree of saturation of macro-pores $S_{\mathrm{r}}^{\mathrm{e}}$

113 (Alonso et al., 2010): where $S_{\mathrm{r}}^{\mathrm{m}}$ the degree of saturation of micro-pores. This method can improve the prediction of effective stress, but still overestimates the contribution of suction in

117 some cases (Sheng et al., 2011; Zhai et al., 2019). which satisfies Houlsby's power equation. DETERMINING BISHOP'S PARAMETER $\chi$ BASED ON MACROPOROSITY

121 Fig. 1 shows a conceptual sketch of water retention curves at two different void ratios 122 (Vaunat \& Casini, 2017). The incremental change in water ratio $\delta e_{\mathrm{w}}$ (path OB) caused 123 either by suction change or mechanical loading can be split into $\delta e_{\mathrm{w} 1}$ (path OA) and $124 \delta e_{\mathrm{w} 2}$ (path $\left.\mathrm{AB}\right)$. The change of water content along path $\mathrm{OA}$ is caused by the increment 125 of suction at constant volume, while the incremental component of path $\mathrm{AB}$ is caused 126 by the change of void ratio under constant suction (net stress effect). This latter can 127 be expressed as a proportion of total volume change (Vaunat \& Casini, 2017). The total incremental work input per unit volume in unsaturated soils $\delta w$ (Houlsby, 1997) 
can be expressed as:

$$
\begin{aligned}
\delta w & =-\left[\sigma-\alpha u_{\mathrm{w}}-(1-\alpha) u_{\mathrm{a}}\right] \frac{\delta V_{V}}{V}-\left(u_{\mathrm{a}}-u_{\mathrm{w}}\right) \frac{\delta V_{\mathrm{w} 1}}{V} \\
& =-\left[\sigma-\alpha u_{\mathrm{w}}-(1-\alpha) u_{\mathrm{a}}\right] \delta \varepsilon_{V}-\left(u_{\mathrm{a}}-u_{\mathrm{w}}\right) \frac{\delta V_{w 1}}{V}
\end{aligned}
$$

where $\sigma$ is the total mean stress; $V$ is the total soil volume; $V_{V}$ is the volume of voids; $\delta V_{\text {w1 }}$ is the change of volume occupied by water due to suction; $\alpha$ is the ratio of the increment of volume occupied by water caused by the incremental volumetric strain under constant suction to the pore volume increment. As the first term between brackets in Eq. (6) expresses Bishop's effective stress, Vaunat \& Casini (2017) proposed:

$$
\chi=\alpha=\frac{\delta V_{\mathrm{w} 2}}{\delta V_{\mathrm{V}}}=\frac{\delta e_{\mathrm{w} 2}}{\delta e}
$$

where $\delta e_{\mathrm{w} 2}$ is the increment of water ratio caused by the change of volumetric strain under constant suction; $\delta e$ is the increment of void ratio.

Fig. 2 shows the SWRCs under different void ratios for several soils (Li et al., 2007; Salager et al., 2013; Seiphoori et al., 2014; Gao \& Sun, 2017). It appears that in low suction range, the water retention curve is dependent on void ratio. By contrast, in higher suction range, the SWRCs are almost the same (Fig. 3). The separating point corresponds to the delimitation between the range of capillary water in macro-pores and the range of adsorbed water in micro-pores (Romero, 1999). Mašín (2013) also discussed the structure evolution with mechanical loading and assumed that loading (compaction) influenced predominantly the macro-pores, while micro-pores remained untouched (Fig. 3). Thus, as the volume change is mainly due to macro-pores changes, Bishop's parameter $\chi$ is solely related to the low suction range (Fig. 3). Thereby, Eq. 
(7) is modified as:

$$
\chi=\frac{\delta e_{\mathrm{w} 2}-\delta e_{\mathrm{w}}^{m}}{\delta e-\delta e^{\mathrm{m}}}
$$

153 where $\delta e_{\mathrm{w}}^{m}$ is the incremental microscopic water ratio; $\delta e^{\mathrm{m}}$ is the incremental 154 microscopic void ratio. In Fig. 3, two SWRCs at different void ratios should be 155 provided and the void ratio of every SWRC should be kept constant in the whole 156 suction range. However, in a SWRC test, the void ratio changes with suction changes.

157 As the pore size distribution (PSD) obtained by Mercury Intrusion Porosimetry (MIP) 158 test can be used to determine the SWRC at a constant void ratio (Zhang et al., 2018), 159 the parameters in Eq. (8) can be obtained using two different PSDs, as illustrated in 160 Fig. 4.

\section{EVALUATION OF THE PROPOSED METHOD THROUGH SHEAR} STRENGTH Bishop \& Blight (1963) described the shear strength of unsaturated soils by:

$$
\tau_{f}=c^{\prime}+\left[\left(\sigma_{\mathrm{n}}-u_{\mathrm{a}}\right)+\chi\left(u_{\mathrm{a}}-u_{\mathrm{w}}\right)\right] \tan \theta^{\prime}
$$

where $\tau_{f}$ is the shear strength; $c^{\prime}$ is the effective cohesion at saturated state; $\sigma_{n}$ is 166 the normal stress; $\theta^{\prime}$ is the internal friction angle. Using Eq. 9 and considering 167 triaxial conditions, parameter $\chi$ can be back-calculated, as follows:

$$
\chi=\frac{\frac{q_{\mathrm{f}}-c \prime \frac{6 \cos \theta \prime}{3-\sin \theta \prime}}{M}-\bar{p}}{s}
$$
where $q_{\mathrm{f}}$ is the deviator stress at failure; $M=6 \sin \phi^{\prime} /\left(3-\sin \phi^{\prime}\right)$ is the slope of critical 170 state line; $\bar{p}=\left[\sigma_{1}+2 \sigma_{3}\right] / 3-u_{\mathrm{a}}$ is the net mean stress.

171 The results from the tests on Nanyang expansive clay were used to validate the 
172 proposed method for Bishop's parameter $\chi$ determination (Fig. 8). Table 1 summarises

173 the physical property indexes and triaxial shear parameters for this clay. Triaxial shear

174 tests were conducted using an unsaturated triaxial testing apparatus supplied by GDS

175 company. In order to obtain the molded samples only in drying process, all triaxial

176 specimens were prepared by static compaction at initial water content of about 0.215

177 (suction is about $170 \mathrm{kPa}$ ) and initial dry density around $1.25 \mathrm{Mg} / \mathrm{m}^{3}$. Table 2 gives a

178 summary of the test conditions and stress paths. For tests No.1-3, suction was applied

179 using axis-translation technique in triaxial cell, while for tests No.4 and No.5 the

180 suctions (0.8 and 2.5 MPa, respectively ) were applied through controlling the water

181 contents ( $w=14.8 \%$ and $w=12.55 \%$, respectively) by referring to the SWRC in drying

182 process. For higher suctions, i.e. tests No.6-8, the vapor equilibrium method was

183 employed. When the samples of tests No.4-8 reached the target respective suctions,

184 they were put into triaxial cell for further consolidation and shear tests following the

185 stress and suction paths shown in Figs. 5 (a) and (b). The net confining pressure was

$186100 \mathrm{kPa}$, and the suctions were $0.05,0.2,0.4,0.8,2.5,3.29,38$ and $368 \mathrm{MPa}$,

187 respectively. In the triaxial shear tests, $q_{\mathrm{f}}$ and $\bar{p}$ were measured for every suction state

188 and given in Table 3. As illustrated in Fig. 2, when the suction is higher than a specific

189 value, the water retention curve is independent of void ratio. In addition, the modulus

190 of soils with high suction are normally very large and the changes of void during shear

191 tests are thus small. Thereby, shear tests under constant water content are often

192 considered as under constant suction in high suction range (Gao et al., 2019; Zhang

193 et al., 2020). Substitution of $q_{\mathrm{f}}, \bar{p}, c^{\prime} \theta^{\prime}$ and $s$ (see Tables 1, 2 and 3) into Eq. (10) 
194 allows the calculation of Bishop's parameter $\chi$ for every suction (or degree of 195 saturation), as illustrated in Fig. 8.

As the void ratio of this sample with $3.29 \mathrm{MPa}$ in shear test is 0.99 , the PSD 197 curves of two samples compacted at different void ratios (0.81 and 0.92) at the same 198 constant suction of $3.29 \mathrm{MPa}$ are considered. The results are shown in Fig. 6 . 199 According to Lloret et al. (2003), the macro- and micro-pores are separated by the 200 point where the PSD becomes independent of loading. For bimodal structure, the 201 diameter at the valley bottom between the two pore size families can be considered as 202 the delimiting diameter between micro- and macro-pores. It appears from Fig. 6 that 203 the PSD curves are not affected by the compaction load when the pore diameter is 204 smaller than $4900 \mathrm{~nm}$. Thereby, this diameter was taken as the boundary between 205 macro- and micro-pores. Eq. (8) can then be applied to determine Bishop's parameter $206 \chi$ using the macro-PSDs. Fig. 7 shows the obtained results. For comparison, the 207 parameters in Table 1 are substituted into Eq. (10), and several other methods are 208 applied including Bishop's method with $\chi=S_{r}$ (Eq. 2), Vanapalli et al.'s method (Eq. 209 3), Zhou et al.'s method (Eq. 4), Alonso et al.'s method (Eq. 5), and Vaunat \& Casini's 210 method (Eq. 7). Results are included in Fig. 8. It is observed that when the global 211 degree of saturation (Eq. 2) is considered as Bishop's parameter $\chi$, significant 212 overestimation of suction contribution is obtained, in agreement with the observation 213 of Alonso et al. (2010) and Zhou et al. (2016). In Zhou et al.'s method, the capillary 214 water is separated from the adsorbed water. Then the capillary degree of saturation 215 (Eq. 4) is used to determine Bishop's parameter $\chi$. Fig. 7 shows the fitted SWRCs by 
217 relationship between capillary degree of saturation and degree of saturation is plotted

218 in Fig. 8. It appears that this method underestimates the suction contribution to

219 Bishop's effective stress over a wide suction range. In Alonso et al.'s method, $S_{\mathrm{r}}^{\mathrm{m}}$ is

220 the degree of saturation of the micro-pores with diameter smaller than $4900 \mathrm{~nm}$. It

221 was found to be about $20 \%$ by calculation based on the PSD in Fig. 6 . The effective

222 degree of saturation (Eq. 5) is used to determine $\chi$. It appears that the prediction is

223 improved, but the suction contribution is overestimated. Similarly, Vaunat \& Casini's

224 method can improve the prediction in the low suction range as Alonso et al.'s method,

225 but remains unsatisfactory in the higher suction range. In particular, a small bump on

226 the curve obtained by Vaunat \& Casini's method appears in the range of degree of

227 saturation from $5 \%$ to $40 \%$, owing to the contribution of micro-pores to the calculation

228 of $\chi$. In Vanapalli et al.'s method, a value of 1.6 was fitted for exponent parameter $\lambda$.

229 It is observed that the prediction matches the test data well in the low suction range,

230 but gives higher $\chi$ values in higher suction range. Interestingly, the proposed method

231 (Eq. 8) shows a good agreement with the experimental results in the full suction range.

\section{CONCLUSIONS}

233 The hydro-mechanical behavior of unsaturated soils is strongly related to the water

234 distribution in pores. As loading and drying predominantly affect the macro-pores,

235 with the micro-pores remaining almost undisturbed, the pore size below which the

236 PSD curves become independent of loading or drying processes can be considered as

237 the delimiting diameter between macro-and micro-pores. This also implies that the 
contribution of suction to Bishop's effective stress is only related to the water in macro-pores.

240 Based on a method proposed by Vaunat \& Casini (2017) for Bishop's parameter

$241 \chi$ determination, a modified method was proposed considering the contribution of 242 capillary water in macro-pores. Bishop's parameter $\chi$ was defined as the ratio of the 243 change in -water volume to the change in macro-pores during a loading process at 244 constant suction. When the degree of saturation of macro-pores is zero, $\chi$ becomes 245 zero too. The proposed method was evaluated using experimental shear strength data 246 and compared with different methods reported in literature. It appeared that the 247 proposed method allows good agreement between the prediction and measurement 248 over a wide suction range, as opposed to other methods which either overestimate or 249 underestimate the suction contribution to the effective stress. It is however worth 250 noting that more test results are needed to further validate the proposed method.

\section{ACKNOWLEDGEMENTS}

253 The authors are grateful to the China Scholarship Council (CSC grant No. 254 201806060075), Ecole des Ponts ParisTech and Guilin University of Technology. 


\section{References}

Alonso, E. E., Pereira, J. M., Vaunat, J. \& Olivella, S. (2010). A microstructurallybased effective stress for unsaturated soils. Géotechnique 60, No. 12, 913-925.

Bishop, A. W. (1959). The principle of effective stress. Tek. Ukebl.106, No. 39, 859863.

Bishop, A. W. \& Blight, G. E. (1963). Some aspects of effective stress in saturated and partly saturated soils. Géotechnique 13, No. 3, 177-197.

Coleman J.D.1962. Stress strain relations for partly satured soil. Correspondence, Géotechnique 12, No. 4, 348-350.

Cui Y. J. \& Delage P. (1996). Yielding and plastic behaviour of an unsaturated compacted silt. Géotechnique 46, No. 2, 291-311.

Fredlund, D. G. \& Morgenstern, N. R. (1977). Stress state variables for unsaturated soils. J. Geotech. Geoenviron. Engng 103 (ASCE 12919).

Gao, Y. \& Sun, D. A. (2017). Soil-water retention behavior of compacted soil with different densities over a wide suction range and its prediction. Comput. Geotech. 91, 17-26.

Gao, Y., Sun, D., Zhou, A. \& Li, J. (2018). Effect of stress state on soil-water retention and its application on the strength prediction. Géotech. Lett. 8, No. 4, 324-329.

Gao, Y., Sun, D. A., Zhu, Z., \& Xu, Y. (2019). Hydromechanical behavior of unsaturated soil with different initial densities over a wide suction range. Acta Geotech., 14(2), 417-428.

Gao, Y., Sun, D. A., Zhou, A., \& Li, J. (2020). Predicting Shear Strength of 
Garven, E. A. \& Vanapalli, S. K. (2006). Evaluation of empirical procedures for predicting the shear strength of unsaturated soils. In Unsaturated Soils 2006 (pp. 2570-2592).

Houlsby, G. T. (1997). The work input to an unsaturated granular material. Géotechnique 47, No. 1, 193-6.

Konrad, J. M. \& Lebeau, M. (2015). Capillary-based effective stress formulation for

Li, J., Sun, D. A., Sheng, D. C., Sloan, S. \& Fredlund, D. G. (2007). Preliminary study on soil water characteristics of Maryland clay. In Proceedings of the 3rd Asian Conference on Unsaturated Soils, Nanjing, China, 569-574.

Liu, Y., Wei, C. F., Zhao, C. G., Fang, Q. \& Li, J. (2018). Work input for unsaturated soils considering interfacial effects. Int. J. Numer. Anal Methods in Geomech. 42, No. 9, 1078-1094.

Lloret, A., Villar, M. V., Sanchez, M., Gens, A., Pintado, X. \& Alonso, E. E. (2003). Mechanical behaviour of heavily compacted bentonite under high suction changes.

298 Mašín, D. (2013). Double structure hydromechanical coupling formalism and a model for unsaturated expansive clays. Engng Geol. 165, 73-88. 
Monroy, R., Zdravkovic, L. \& Ridley, A. (2010). Evolution of microstructure in compacted London Clay during wetting and loading. Géotechnique 60, No. 2, 105119.

Pereira, J. M., Wong, H., Dubujet, P., \& Dangla, P. (2005). Adaptation of existing behaviour models to unsaturated states: application to CJS model. Int. J. Numer. Anal. Methods Geomech., 29, No. 11, 1127-1155.

Romero Morales, E. E. (1999). Characterisation and thermo-hydro-mechanical behaviour of unsaturated Boom clay: an experimental study. Ph.D. thesis. Universitat Politècnica de Catalunya.

Salager, S., Nuth, M., Ferrari, A. \& Laloui, L. (2013). Investigation into water retention behaviour of deformable soils. Can. Geotech. J. 50, No. 2, 200-208.

Seiphoori, A., Ferrari, A. \& Laloui, L. (2014). Water retention behaviour and microstructural evolution of MX-80 bentonite during wetting and drying cycles. Géotechnique 64, No. 9, 721-734.

Sheng, D., Sloan, S. W. \& Gens, A. (2004). A constitutive model for unsaturated soils: thermomechanical and computational aspects. Comput. Mech. 33, No. 6, 453-465.

Sheng, D., Zhou, A. \& Fredlund, D. G. (2011). Shear strength criteria for unsaturated soils. Geotech. Geol. Eng. 29, No. 2, 145-159.

Vanapalli, S. K., Fredlund, D. G., Pufahl, D. E. \& Clifton, A. W. (1996). Model for the prediction of shear strength with respect to soil suction. Can. Geotech. J. 33, No. 3, 379-392.

Vaunat, J. \& Casini, F. (2017). A procedure for the direct determination of Bishop's 

636.

324 Wheeler, S. J., Sharma, R. S. \& Buisson, M. S. R. (2003). Coupling of hydraulic 325 hysteresis and stress-strain behaviour in unsaturated soils. Géotechnique 53, No. $1,41-54$

327 Zhai, Q. Rahardjo, H., Satyanaga, A., \& Dai, G. (2019). Estimation of unsaturated 328 shear strength from soil-water characteristic curve. Acta Geotech. 14, 1977-1990. 329 Zhang, F., Cui, Y., Zeng, L., Robinet, J. C., Conil, N. \& Talandier, J. (2018). Effect 330 of degree of saturation on the unconfined compressive strength of natural stiff clays with consideration of air entry value. Engng Geol. 237, 140-148.

332 Zhang, J., Niu, G., Li, X. \& Sun, D. A. (2020). Hydro-mechanical behavior of expansive soils with different dry densities over a wide suction range. Acta Geotech. 15, No. 1, 265-278.

Zhou, A., Huang, R. \& Sheng, D. (2016). Capillary water retention curve and shear strength of unsaturated soils. Can. Geotech. J. 53, No. 6, 974-987.

337 Zhou, A., Wu, S., Li, J. \& Sheng, D. (2018). Including degree of capillary saturation into constitutive modelling of unsaturated soils. Comput Geotech. 95, 82-98. 
Table captions.

340 Table 1 Physical property indexes and shear strength parameters of Nanyang weakly

341 expansive soil

342 Table 2 Relevant state variables in triaxial tests

343 Table 3 Stress state at triaxial shear failure

344 Figure captions.

345 Fig. 1 Partition of total water volume change into components due to suction and

346 deformation only for a path going from the water retention curve at $e$ to $e+\delta e$ (after

347 Vaunat \& Casini, 2017)

348 Fig. 2. SWRCs under different void ratios over a wide suction range for soils: (a) a

349 clayey silty sand (data from after Salager et al., 2013); (b) MX-80 granular bentonite

350 (data from Seiphoori et al., 2014); (c) Maryland clay (data from Li et al., 2007); (d)

351 Pearl clay (data from Gao \& Sun, 2017)

352 Fig. 3 Sketches of soil-water retention behavior of specimens with different densities

353 over a wide suction range

354 Fig. 4 PSDs at two different void ratios (compacted at different void ratios at a 355 constant suction)

356 Fig. 5 Stress and suction paths for tests: (a) tests in the lower suction range; (b) tests

357 in the higher suction range

358 Fig. 6 The PSD of Nanyang weakly expansive soil and the criterion adopted to

359 discriminate macro- and micro-pores

360 Fig. 7 Measured SWRC and fitted curves from Zhou et al.' SWRC method (2016) for

$361 \quad$ Nanyang weakly expansive soil

362 Fig. 8 Comparison of measured Bishop's parameter $\chi$ with the predictions obtained

363 by various methods for Nanyang weakly expansive soil 
365 Table 1 Physical property indexes and shear strength parameters of Nanyang weakly expansive

366 soil

\begin{tabular}{cccccccccc}
\hline $\begin{array}{c}\text { Specific } \\
\text { gravity }\end{array}$ & $\begin{array}{c}\text { Liquid } \\
\text { limit } \\
(\%)\end{array}$ & $\begin{array}{c}\text { Plastic } \\
\text { limit } \\
(\%)\end{array}$ & $\begin{array}{c}\text { Plasticity } \\
\text { index }\end{array}$ & $\begin{array}{c}\text { Shrinkage } \\
\text { limit }(\%)\end{array}$ & $\begin{array}{c}\text { Maximum } \\
\text { dry density } \\
\left(\mathrm{g} / \mathrm{cm}^{3}\right)\end{array}$ & $\begin{array}{c}\text { Optimum } \\
\text { water } \\
\text { content }(\%)\end{array}$ & $\begin{array}{c}\text { Free } \\
\text { swelling } \\
\text { ratio }(\%)\end{array}$ & $\begin{array}{c}\text { Effective } \\
\text { cohesion } \\
(\mathrm{kPa})\end{array}$ & $\begin{array}{c}\text { Effective } \\
\text { friction angle } \\
\left({ }^{\circ}\right)\end{array}$ \\
\hline 2.74 & 38.8 & 17.2 & 21.6 & 10.5 & 1.69 & 18.2 & 53.8 & 10.4 & 20.8 \\
\hline
\end{tabular}

367

368

369

Table 2 Relevant state variables in triaxial tests

\begin{tabular}{|c|c|c|c|c|c|c|c|c|c|}
\hline \multirow{2}{*}{$\begin{array}{l}\text { Test } \\
\text { No. }\end{array}$} & \multicolumn{3}{|c|}{ Molding state } & \multicolumn{3}{|c|}{$\begin{array}{l}\text { Before triaxial } \\
\text { shearing }\end{array}$} & \multirow{2}{*}{$\begin{array}{l}\text { Suction } \\
(\mathrm{MPa})\end{array}$} & \multirow{2}{*}{$\begin{array}{l}\text { Control suction } \\
\text { method }\end{array}$} & \multirow{2}{*}{$\begin{array}{c}\text { Net cell } \\
\text { pressure }(\mathrm{kPa})\end{array}$} \\
\hline & $w_{0}$ & $S_{\mathrm{r} 0}(\%)$ & $e_{0}$ & $w$ & $S_{\mathrm{r}}(\%)$ & $e$ & & & \\
\hline 1 & 21.50 & 48.45 & 1.216 & 24.14 & 79.13 & 0.826 & 0.05 & \multirow{3}{*}{$\begin{array}{l}\text { Axis-translation } \\
\text { technique }\end{array}$} & \multirow{8}{*}{100} \\
\hline 2 & 22.01 & 50.13 & 1.203 & 19.12 & 52.79 & 0.982 & 0.20 & & \\
\hline 3 & 21.50 & 48.97 & 1.203 & 17.07 & 45.30 & 1.02 & 0.40 & & \\
\hline 4 & 21.64 & 49.54 & 1.197 & 14.80 & 38.44 & 1.04 & 0.80 & \multirow{2}{*}{ Air-drying } & \\
\hline 5 & 21.78 & 49.57 & 1.204 & 12.55 & 35.52 & 0.957 & 2.50 & & \\
\hline 6 & 21.86 & 49.95 & 1.199 & 11.90 & 32.53 & 0.996 & 3.29 & \multirow{3}{*}{$\begin{array}{c}\text { Vapor equilibrium } \\
\text { technique }\end{array}$} & \\
\hline 7 & 21.72 & 49.51 & 1.202 & 6.60 & 19.57 & 0.924 & 38.0 & & \\
\hline 8 & 21.76 & 49.52 & 1.204 & 4.10 & 12.20 & 0.907 & 367.5 & & \\
\hline
\end{tabular}

Table 3 Stress state at triaxial shear failure

\begin{tabular}{|c|c|c|c|c|}
\hline $\begin{array}{l}\text { Test } \\
\text { No. }\end{array}$ & $\begin{array}{l}\text { Control suction } \\
\text { method }\end{array}$ & $\begin{array}{c}\text { Net cell } \\
\text { pressure }(\mathrm{kPa})\end{array}$ & $\begin{array}{c}\text { Deviator stress } \\
q_{\mathrm{f}}(\mathrm{kPa})\end{array}$ & $\begin{array}{c}\text { Net mean stress } \\
\bar{p}(\mathrm{kPa})\end{array}$ \\
\hline 1 & \multirow{3}{*}{$\begin{array}{c}\text { Axis-translation } \\
\text { technique }\end{array}$} & \multirow{8}{*}{100} & 140 & 146 \\
\hline 2 & & & 210 & 160 \\
\hline 3 & & & 280 & 196 \\
\hline 4 & \multirow{2}{*}{ Air-drying } & & 320 & 210 \\
\hline 5 & & & 600 & 300 \\
\hline 6 & \multirow{3}{*}{$\begin{array}{c}\text { Vapor equilibrium } \\
\text { technique }\end{array}$} & & 660 & 326 \\
\hline 7 & & & 1290 & 550 \\
\hline 8 & & & 1680 & 660 \\
\hline
\end{tabular}




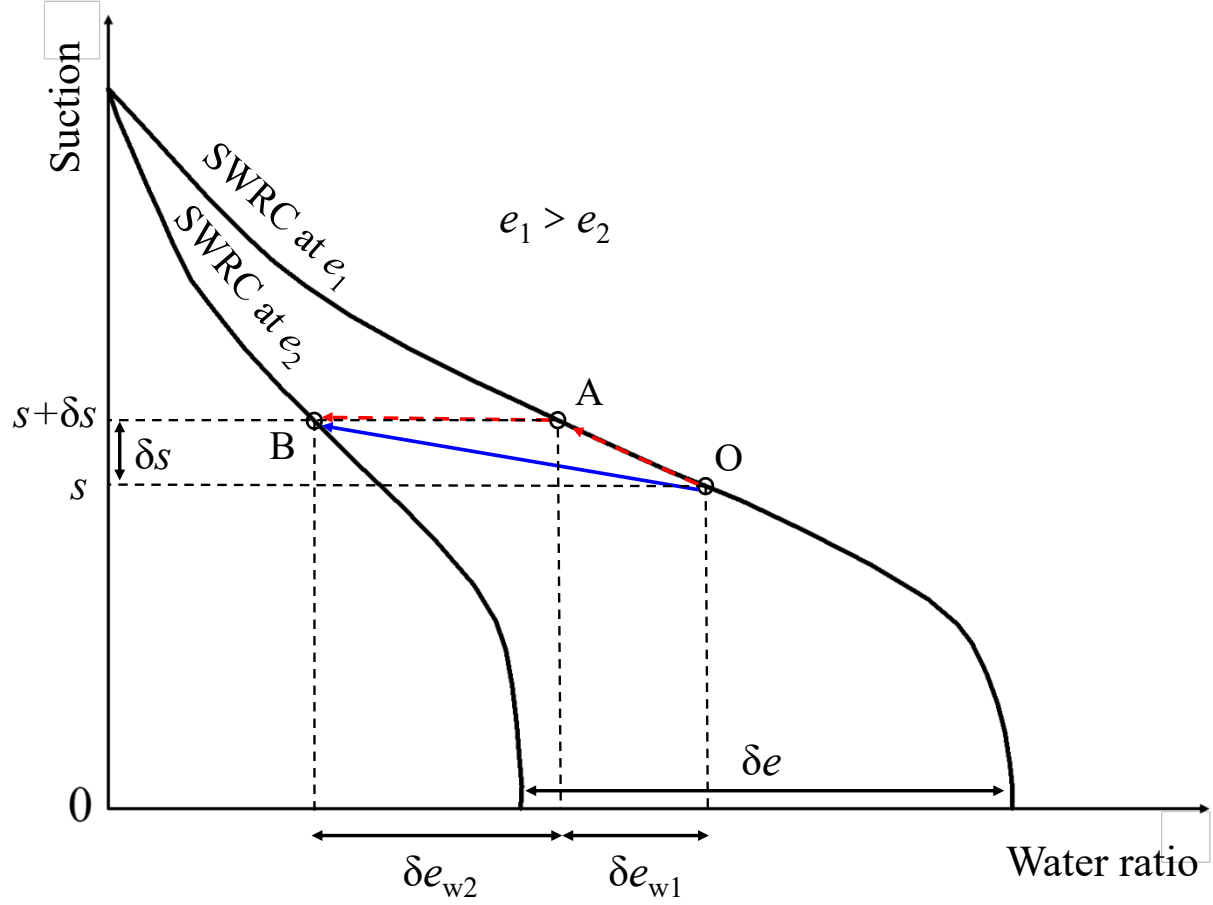

375 Fig. 1. Partition of total water volume change into components due to suction and 376 deformation only for a path going from the water retention curve at $e$ to $e+\delta e$ (after 377 Vaunat \& Casini, 2017) 


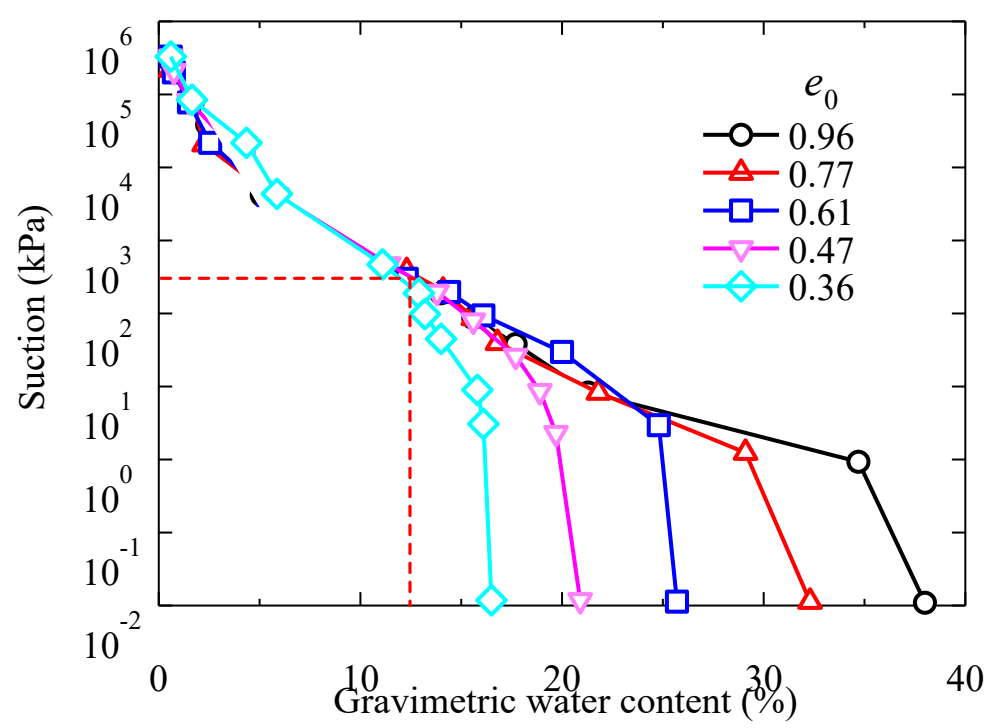

(a)

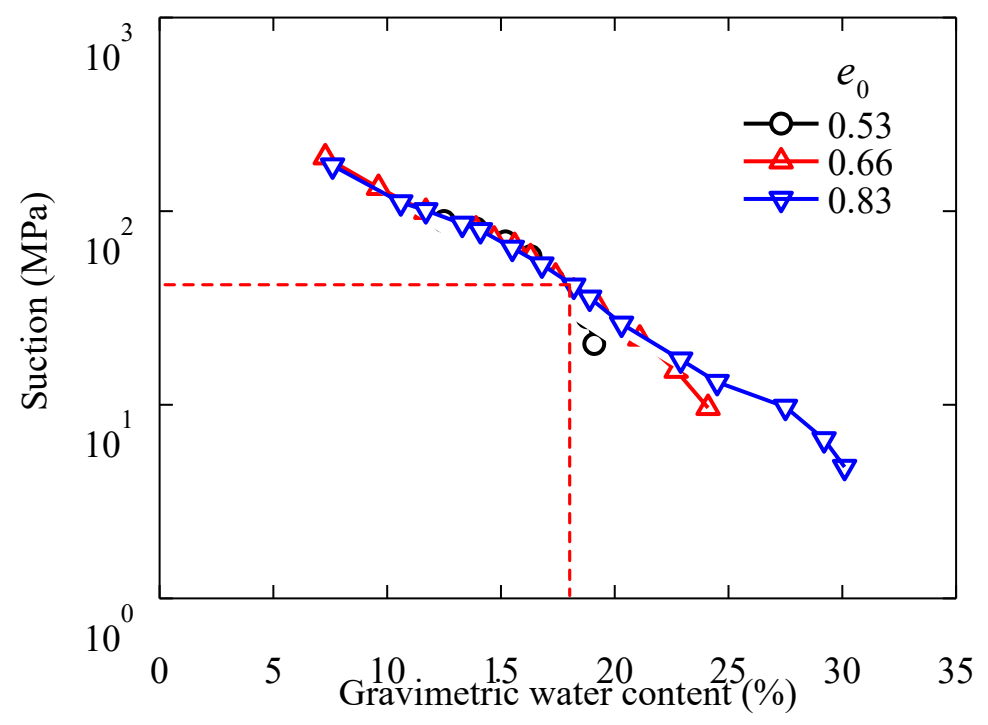

(b) 


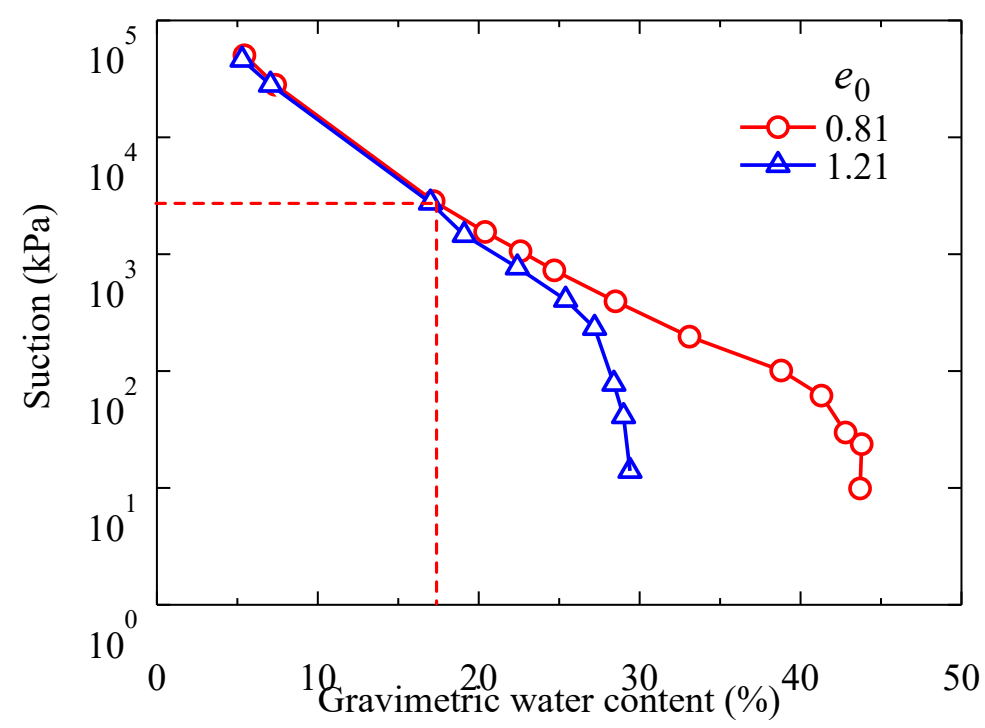

(c)

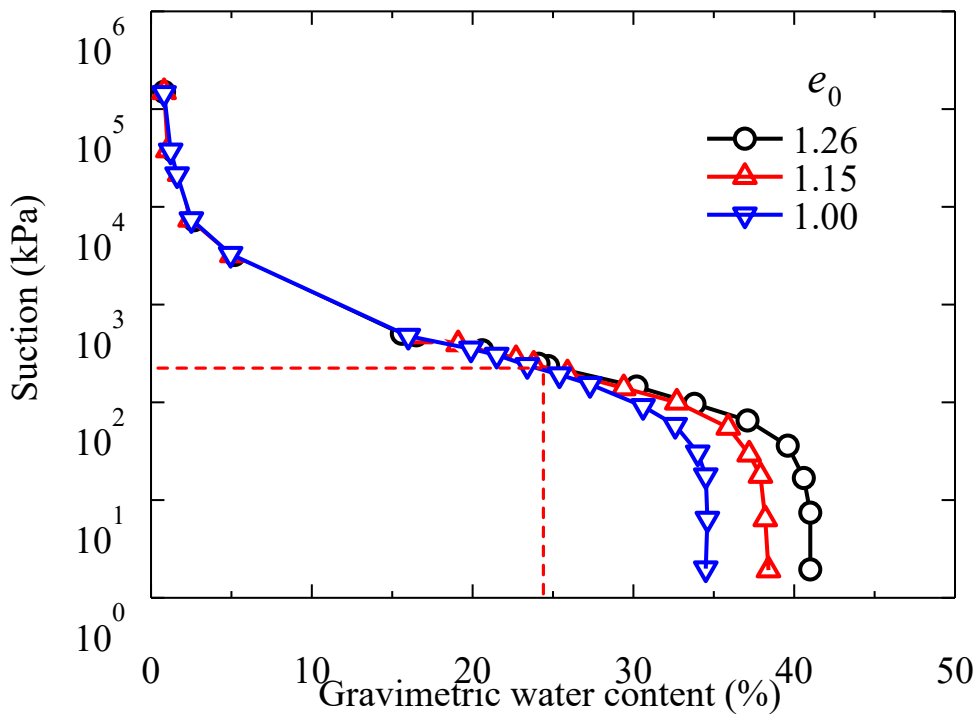

(d)

384 Fig. 2. SWRCs under different void ratios over a wide suction range for soils: (a) a 385 clayey silty sand (data from after Salager et al., 2013); (b) MX-80 granular bentonite 386 (data from Seiphoori et al., 2014); (c) Maryland clay (data from Li et al., 2007); (d) 387 Pearl clay (data fron Gao \& Sun, 2017) 


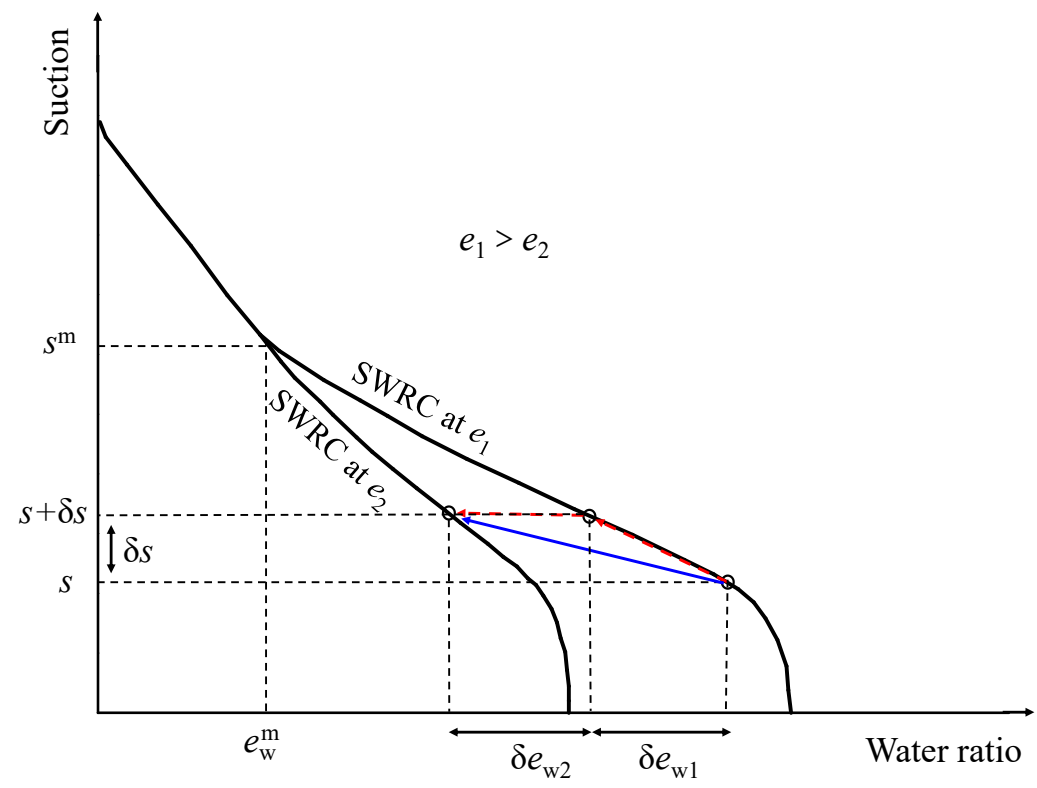

389 Fig. 3. Sketches of soil-water retention behavior of specimens with different densities 390 over a wide suction range

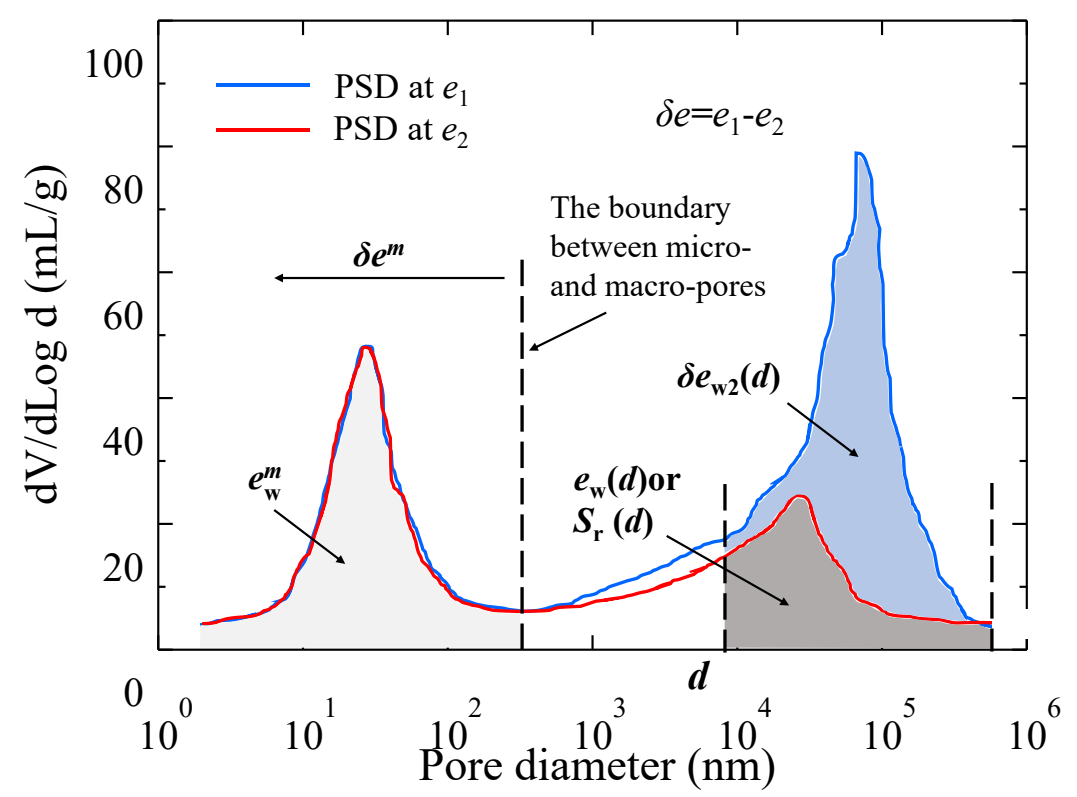

392 Fig. 4. PSDs at two different void ratios (compacted at different void ratios at a 393 constant suction) 


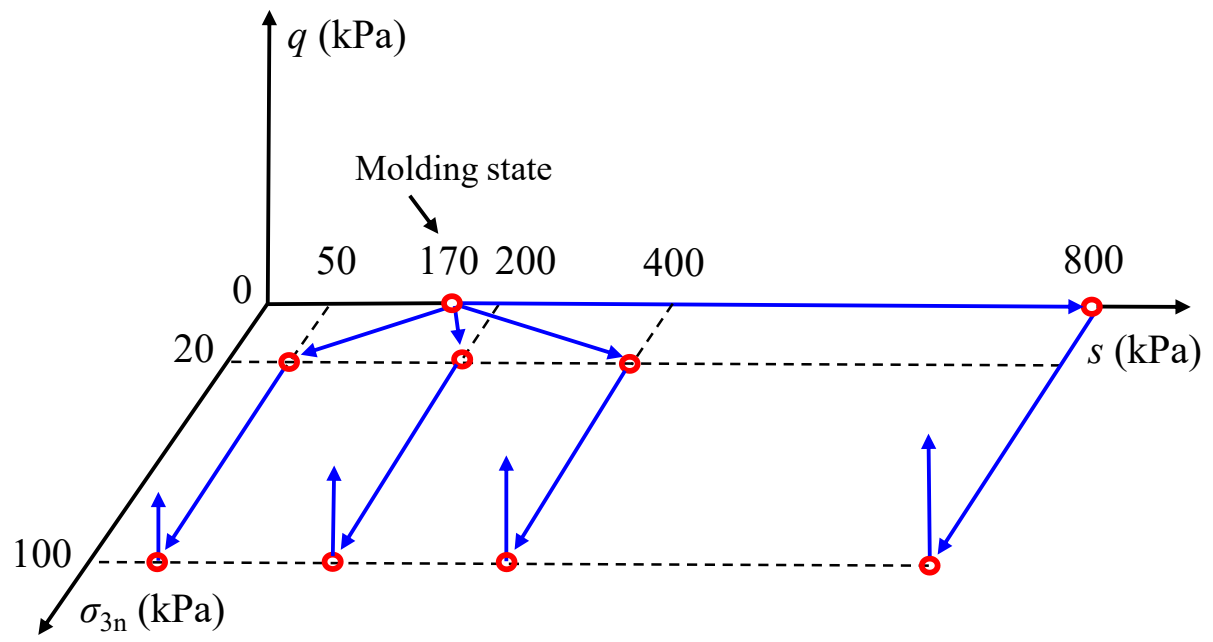

(a)

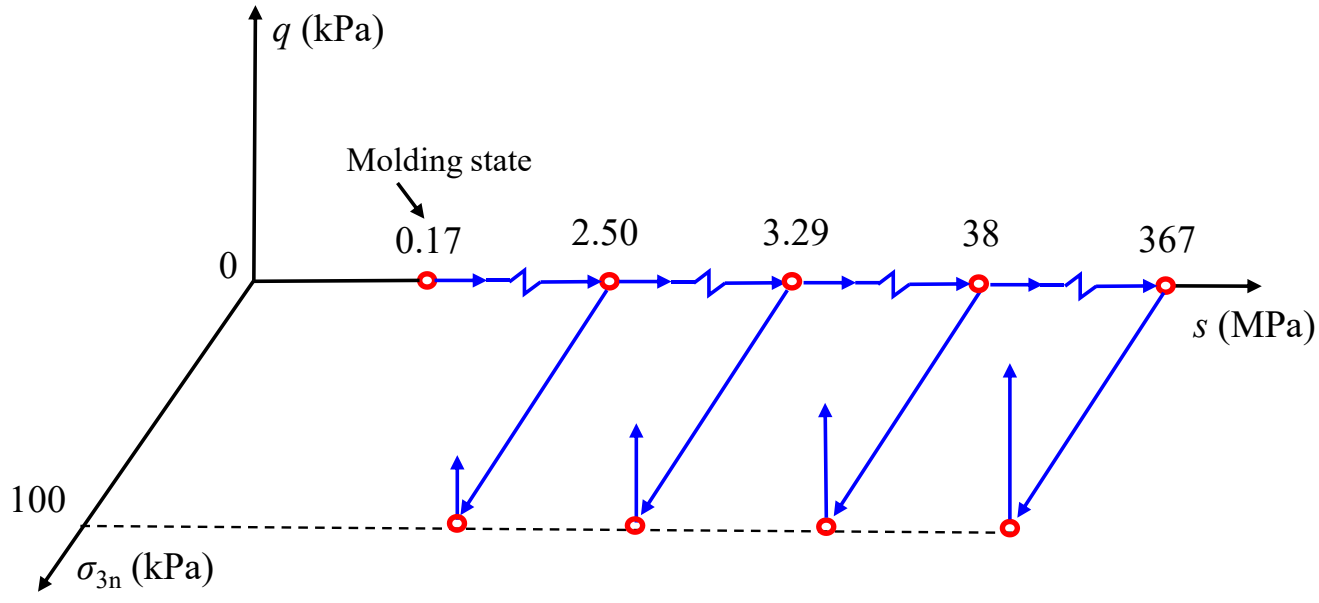

(b)

398 Fig. 5. Stress and suction paths for tests: (a) tests in the lower suction range; (b) tests 399 in the higher suction range 


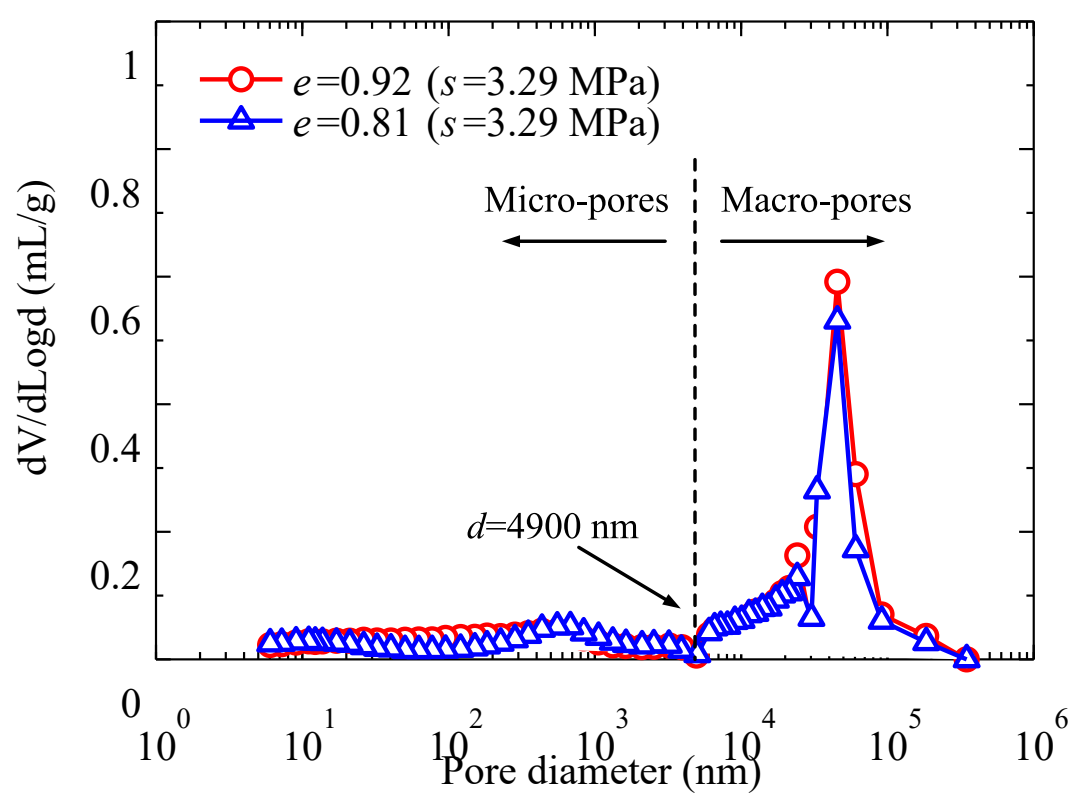

402 Fig. 6. The PSDs of Nanyang weakly expansive soil and the criterion adopted to discriminate macro- and micro-pores

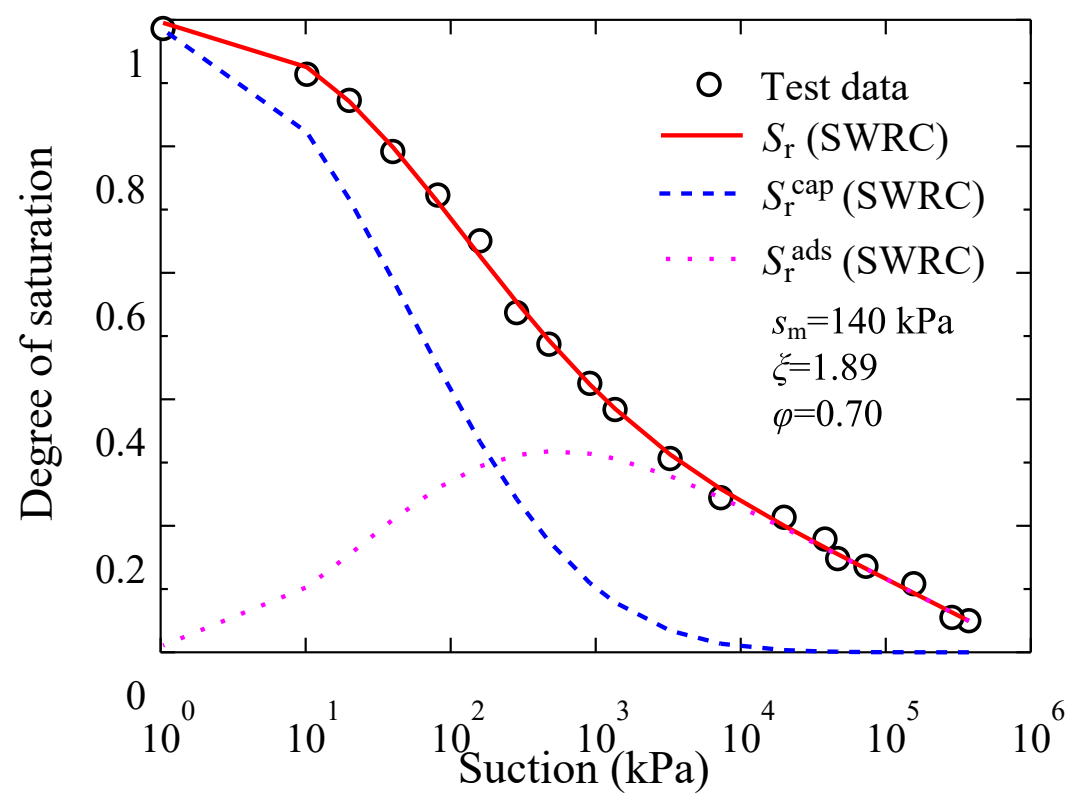

405 Fig. 7 Measured SWRC and fitted curves from Zhou et al.' SWRC method (2016)

406 for Nanyang weakly expansive soil 


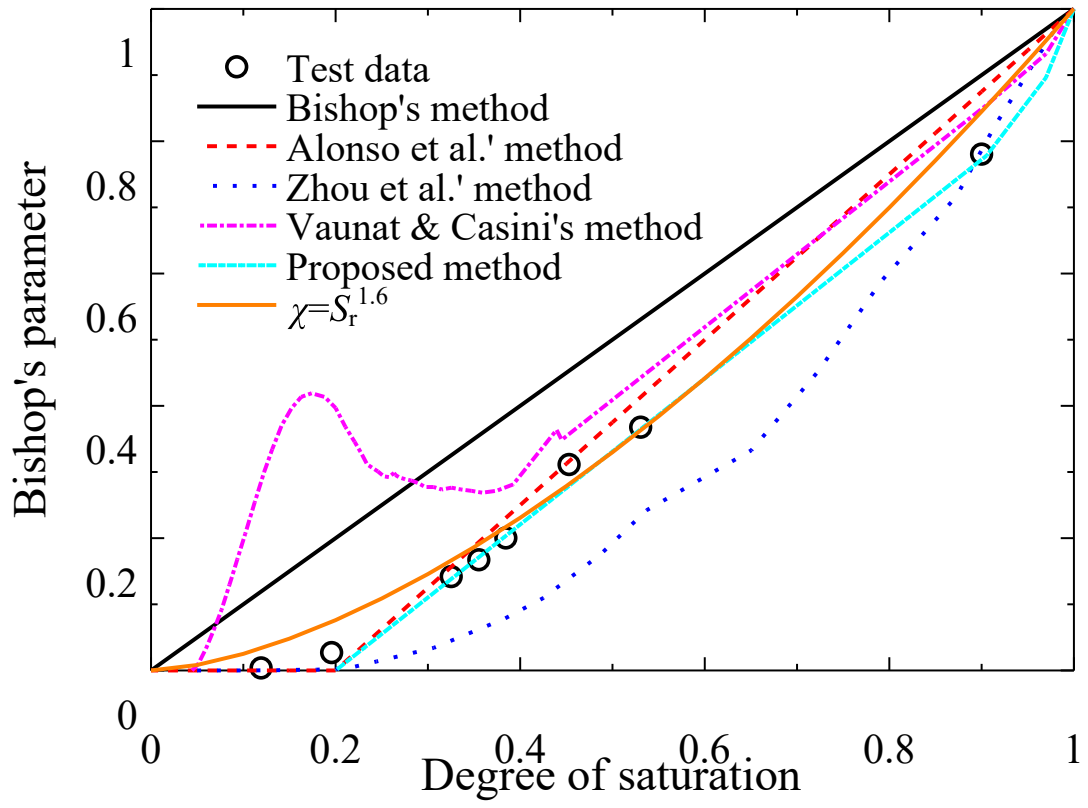

408 Fig. 8. Comparison of measured Bishop's parameters $\chi$ with the predictions obtained 409 by various methods for Nanyang weakly expansive soil 